\title{
The oncometabolite D-2-hydroxyglutarate induces angiogenic activity through the vascular endothelial growth factor receptor 2 signaling pathway
}

\author{
JIYOON SEOK ${ }^{1 *}$, SOO-HYUN YOON ${ }^{1,2^{*}}$, SUN-HEE LEE ${ }^{1,2}$, \\ JONG HWA JUNG ${ }^{2}$ and YOU MIE LEE ${ }^{1,2}$ \\ ${ }^{1}$ BK21 Plus KNU Multi-Omics based Creative Drug Research Team, and \\ ${ }^{2}$ Research Institute of Pharmaceutical Sciences, College of Pharmacy, \\ Kyungpook National University, Daegu 41566, Republic of Korea
}

Received July 18, 2018; Accepted November 12, 2018

DOI: 10.3892/ijo.2018.4649

\begin{abstract}
The mutation of isocitrate dehydrogenase (IDH)1 $(\mathrm{R} 132 \mathrm{H})$ and $I D H 2(\mathrm{R} 172 \mathrm{~K})$ and the induction of hypoxia in various solid tumors results in alterations in metabolic profiles, including the production of the D- or L-forms of 2 -hydroxyglutarate $(2 \mathrm{HG})$ from $\alpha$-ketoglutarate in aerobic metabolism in the tricarboxylic acid (TCA) cycle. However, it is unclear whether the oncometabolite D-2HG increases angiogenesis in endothelial cells. Therefore, in this study, we analyzed the levels of various metabolites, including D-2HG, under hypoxic conditions and in $I D H 2 R 172 \mathrm{~K}$ mutant breast cancer cells by mass spectrometry. We then further evaluated the effects of this metabolite on angiogenesis in breast cancer cells. The results revealed that treatment with D-2HG increased the levels of secreted vascular endothelial growth factor (VEGF) in cancer cells and enhanced endothelial cell proliferation in a concentration-dependent manner. Wound healing and cell migration (examined by Transwell assay) were significantly increased by D-2HG to a level similar to that induced by VEGF. Tube formation was significantly stimulated by $\mathrm{D}-2 \mathrm{HG}$, and chick chorioallantoic membrane angiogenesis was also enhanced by D-2HG. D-2HG activated VEGF receptor (VEGFR)2 and VEGFR2 downstream signaling, extracellular signal-regulated kinase $1 / 2$, focal adhesion kinase, AKT and matrix metalloproteinase (MMP)2. Taken together, the findings of this study suggested that D-2HG induced angiogenic activity via VEGFR2 signaling and increased MMP2 activity.
\end{abstract}

Correspondence to: Professor You Mie Lee, College of Pharmacy, Kyungpook National University, 80 Daehakro, Bukgu, Daegu 41566, Republic of Korea

E-mail: lym@knu.ac.kr

*Contributed equally

Key words: D-2-hydroxyglutarate, isocitrate dehydrogenase 2, angiogenesis, vascular endothelial growth factor receptor 2

\section{Introduction}

Hypoxia is defined as a low oxygen concentration of <2\% (1). Hypoxia occurs in inflammation, stroke, tissue ischemia and tumor growth. In the context of hypoxia, cells adapt to the energy production process by minimizing oxygen consumption and converting to corresponding anaerobic processes to stimulate cell growth, anti-apoptotic and angiogenic signaling pathways $(2,3)$. Angiogenesis is a key step in tumor growth and metastasis (4). Several angiogenic molecules, including vascular endothelial growth factor (VEGF), are secreted from cancer cells in response to hypoxic stress; in particular, secreted VEGF increases endothelial cell proliferation, migration and differentiation, thereby affecting cancer progression (5).

Over the past decade, interest in tumor metabolism has increased. Major hallmarks of cancer cells include abnormal metabolism, energy production processes involving the mitochondrial tricarboxylic acid (TCA) cycle and anaerobic digestion processes in the cytoplasm, rather than oxidative phosphorylation, which can use oxygen. This phenomenon was first described by Warburg $(6,7)$ and allows cancer cells to proliferate under hypoxic conditions $\left(\leq 2 \% \mathrm{O}_{2}\right)(8)$. Notably, hypoxia involves a shift from adenosine triphosphate (ATP) production through oxidative phosphorylation to that through glycolysis under normal oxygen conditions. As a result, cancer cells acquire large amounts of energy by converting the majority of glucose to lactic acid. This phenomenon is known as the 'Warburg effect'. In addition, specific mutations in mitochondrial metabolic enzymes have been shown to initiate carcinogenesis (9-11).

Isocitrate dehydrogenase (IDH) 1 and IDH2 are homodimeric enzymes that convert isocitrate to $\alpha$-ketoglutarate $(\alpha-\mathrm{KG})$, reduce $\mathrm{NADP}^{+}$to NADPH, and release carbon dioxide in glutamine, glucose and fatty acid metabolism (12). IDH1 is localized in the cytoplasm, whereas $I D H 2$ is localized in the mitochondria $(13,14)$. Somatic mutations in $I D H 1$ were first observed in patients with glioblastoma (15). IDH2 mutations have also been identified in glioma, albeit much less frequently than IDHI mutations. Moreover, various IDHI/2 point mutations have been identified in acute myeloid leukemia (16), 
chondrosarcoma (17), intrahepatic cholangiocarcinoma (18), angioimmunoblastic T-cell lymphoma (19), gastric cancer (20), colorectal cancer (21) and other types of cancer $(22,23)$. Almost all $I D H 1 / 2$ mutations cause a single amino acid substitution, Arg132 in IDHI (to 1 of 6 amino acid residues: His, Cys, Leu, Ile, Ser, Gly and Val), or corresponding Arg172 in IDH2 (to 1 of 4 different residues: Lys, Met, Gly and Trp) (24). Major mutations are $\mathrm{R} 132 \mathrm{H}$ in $I D H 1$ and $\mathrm{R} 172 \mathrm{~K}$ in $I D H 2$. A new reaction product, 2-hydroxyglutarate ( $2 \mathrm{HG})$, has also been identified in the presence of IDH1/2 mutations. 2HG has two enantiomers, D (or R)-2HG and L (or S)-2HG. Only D-2HG is generated by mutations in IDH1/2. D-2HG, a competitive inhibitor of $\alpha$-KG, inhibits $\alpha$-KG-dependent dioxygenases, such as ten-eleven translocation methylcytosine dioxygenase DNA demethylases, JmjC demethylases and proline hydroxylases, resulting in epigenetic alterations (25-27). D-2HG has been known as an oncometabolite owing to its involvement in diverse biological processes related to tumorigenesis (25-27). This metabolite also directly induces epithelial-mesenchymal transition and increases metastatic potential in colorectal cancer (28). However, D-2HG inhibits hypoxia-inducible factor (HIF) expression by promoting the activity of the HIF-1 prolyl hydroxylases Egl nine homolog (EGLN)1 and EGLN2, suggesting that $\mathrm{D}-2 \mathrm{HG}$ has dual functions as an oncometabolite and tumor suppressor (29). Hypoxia increases the formation of L-2HG independent of the IDH mutation, and elevated L-2HG stabilizes HIF-1 $\alpha$ (30). Therefore, whether D-2HG increases angiogenesis in vitro and in vivo remains unclear, and the mechanisms mediating the angiogenic activities of D-2HG have not yet been elucidated.

Accordingly, in this study, we compared metabolites in the hypoxic state and in human breast cancer cells overexpressing mutant IDH2. Following the identification of D-2HG in this analysis, we further examined the roles of this metabolite in angiogenesis in vitro and ex vivo. The findings of this study may provide important insight into the effects of hypoxia and IDH2 mutations on metabolism and angiogenesis in cancer.

\section{Materials and methods}

Cell culture. HepG2 human liver cancer (Korean Cell Line Bank, Seoul, Korea), The MDA-MB-231 human breast cancer cells, A549 human lung cancer cells, 293T cells (all from ATCC, Manassas, VA, USA) and bovine aortic endothelial cells (BAECs; passages 5-14; Lonza Biosciences, Basel, Switzerland) were grown on culture plates in Dulbecco's modified Eagle's medium (DMEM; HyClone, Logan, UT, USA) supplemented with $10 \%$ fetal bovine serum (FBS; HyClone), $1 \%$ antibiotics (100 U/ml penicillin, $100 \mathrm{mg} / \mathrm{ml}$ streptomycin; Thermo Fisher Scientific, Waltham, MA, USA). The cells were maintained at $37^{\circ} \mathrm{C}$ in an incubator under a humidified atmosphere of $5 \% \mathrm{CO}_{2}$ and $95 \%$ air.

Lentiviral transduction of IDH2 mutants. The lentiviral expression vector for mutant IDH2 [pLenti6.2/V5-IDH2 (R172K)] was kindly provided by Professor Hai Yan of Duke University.Lentiviral particles were packaged by transfecting the 293T cells with pLenti6.2/V5 or pLenti6.2/V5-IDH2 (R172K) (kindly provided by Dr Hai Yan, Duke University Durham, NC, USA) using Polyfect reagent (Qiagen, Valencia, CA, USA) according to the manufacturer's instructions. Following $48 \mathrm{~h}$ of culture in DMEM supplemented with 10\% FBS, viral supernatants were collected and filtered through a $0.45-\mu \mathrm{m}$ syringe filter. The MDA-MB-231 cells were infected with the viral supernatants in the presence of polybrene $(10 \mu \mathrm{g} / \mathrm{ml})$ for $6 \mathrm{~h}$.

Metabolite profiling of cancer cells. The targeted quantitative analysis of metabolites was performed by Human Metabolome Technologies America (HMT, Boston, MA, USA) based on methods previously described (31), using capillary electrophoresis mass spectrometry (Agilent Technologies, Santa Clara, CA, USA). Metabolites were extracted from the MDA-MB-231 cells treated under normoxic or hypoxic conditions for $16 \mathrm{~h}$ and MDA-MB-231 cells that were transduced with IDH2-R172K mutant using lentivirus, as described above, under normoxic conditions. In our results, 116 of the analyzed metabolites were involved in glycolysis; the pentose phosphate pathway (PPP); the TCA (citric acid/Krebs) cycle; the urea cycle; and polyamine, creatine, purine, glutathione, nicotinamide, choline and amino acid metabolism.

Analysis of D-2HG levels in cells. The MDA-MB-231 cells were transduced with lentiviral particles by transfection with pLenti6.2/V5-IDH2 (R172K) or exposed to hypoxic conditions for $24 \mathrm{~h}$. D-2HG contents in cell lysates or medium were then determined using a D-2HG assay kit according to the manufacturer's instructions (BioVision Inc., San Francisco, CA, USA).

Cell counting kit-8 (CCK-8) assays. The BAECs were seeded at $5 \times 10^{3}$ cells/well in 96-well plates and incubated for $24 \mathrm{~h}$. After $24 \mathrm{~h}$, the medium was replaced with low-serum medium (0.5\% FBS in DMEM/low glucose), and the cells were starved for $16 \mathrm{~h}$. Subsequently, the medium was changed to medium containing VEGF $(40 \mathrm{ng} / \mathrm{ml})$ or various concentrations of D-2HG (Sigma-Aldrich, St. Louis, MO, USA). The BAECs were incubated for $24 \mathrm{~h}$, and CCK-8 reagent (10 $\mu \mathrm{l}$; Dojindo Laboratories, Seoul, Korea) was added to each well. The cells were then incubated for $3 \mathrm{~h}$ at $37^{\circ} \mathrm{C}$, and the optical density was measured with a microplate reader (Infinite M200 Pro; Tecan, Mannedorf, Switzerland) at $450 \mathrm{~nm}$.

Enzyme-linked immunosorbent assay (ELISA). The amount of VEGF protein secreted by the A549 human lung cancer cells into the medium was determined using a VEGF ELISA kit (R\&D Systems, Wiesbaden, Germany). The cells were plated in 6-well plates, cultured until reaching 80-90\% confluence, starved with starvation medium (0.5\% FBS in DMEM) for $16 \mathrm{~h}$, and then treated with $\mathrm{D}-2 \mathrm{HG}(250 \mu \mathrm{M}$ or $5 \mathrm{mM})$ for $24 \mathrm{~h}$. The medium was collected, and the amount of VEGF secreted into the medium was quantified using a microplate reader (Infinite M200 Pro; Tecan).

BrdU cell proliferation assays. The BAECs were seeded at $2 \times 10^{3}$ cells/well in 96-well culture plates and then incubated for $24 \mathrm{~h}$. The cells were then starved with $0.5 \%$ FBS in DMEM/low glucose for $16 \mathrm{~h}$. The cells were subsequently incubated with VEGF $(40 \mathrm{ng} / \mathrm{ml})$ for $24 \mathrm{~h}$ in the presence 
of various concentrations of $\mathrm{D}-2 \mathrm{HG}$ in DMEM/low glucose containing $0.5 \%$ FBS. Cell proliferation was measured with a Cell Proliferation ELISA BrdU kit (Roche, Mannheim, Germany).

Ki67 immunofluorescence staining. The BAECs were seeded at $1 \times 10^{4}$ cells/well on coverslips in 4 -well plates and allowed to attach for $24 \mathrm{~h}$. The cells were then starved with $0.5 \% \mathrm{FBS}$ in DMEM/low glucose for $16 \mathrm{~h}$. The cells were incubated with VEGF (40 ng/ml) for $24 \mathrm{~h}$ in the presence of various concentrations of $\mathrm{D}-2 \mathrm{HG}$ in DMEM/low glucose containing $0.5 \% \mathrm{FBS}$. The cells were then fixed with $4 \%$ paraformaldehyde solution and permeabilized with $0.1 \%$ Triton X-100/phosphate-buffered saline (PBS). Fixed cells were blocked with $1 \%$ bovine serum albumin (BSA) in PBS and incubated with anti-Ki67 antibodies (1/200; sc-23900; Santa Cruz Biotechnology, Inc., Dallas, TX, USA) for $3 \mathrm{~h}$ at room temperature. The cells were then incubated for $1 \mathrm{~h}$ at room temperature with Alexa Fluor 488-conjugated anti-rabbit IgG as secondary antibodies (1/200; A-11008; Thermo Fisher Scientific) and Hoechst to label the nuclei (green) and observed under a Leica TCS SP5 II confocal microscope (Leica Microsystems, Wetzlar, Germany).

Transwell migration assay. The chemotactic migration ability of the BAECs was examined using a 24-Transwell system $(6.5 \mathrm{~mm}$ diameter, $8 \mu \mathrm{m}$ pore size; Corning Costar, Lowell, MA, USA). The BAECs were starved in $0.5 \% \mathrm{FBS}$ in DMEM/low glucose for $16 \mathrm{~h}$ and seeded at $1 \times 10^{5}$ cells/well into the upper chambers of the plates with $0.5 \% \mathrm{FBS}$ in DMEM/low glucose. The lower chambers were filled with $600 \mu \mathrm{l}$ of $0.5 \% \mathrm{FBS}$ in DMEM/low glucose with or without VEGF $(40 \mathrm{ng} / \mathrm{ml})$ and $\mathrm{D}-2 \mathrm{HG}(250 \mu \mathrm{M})$ as chemo-attractants. Following incubation at $37^{\circ} \mathrm{C}$ for $24 \mathrm{~h}$, the migrated cells were fixed with $100 \%$ methanol (Merck, Kenilworth, NJ, USA) and stained with hematoxylin and eosin (Sigma-Aldrich).

Wound healing assay. The BAECs were plated at $4 \times 10^{5}$ cells/well on 12 -well plate and allowed to reach $90 \%$ confluence. The BAECs were then starved in $0.5 \%$ FBS in DMEM/low glucose for $16 \mathrm{~h}$ and treated with mitomycin $\mathrm{C}$ $(1 \mu \mathrm{g} / \mathrm{ml})$ for $1 \mathrm{~h}$. Thereafter, cell layers were scratched with a 1-ml micropipette tip. Plates were rinsed with PBS and incubated at $37^{\circ} \mathrm{C}$ for $24 \mathrm{~h}$ with starvation medium with or without VEGF (40 ng/ml) or D-2HG $(250 \mu \mathrm{M})$. Wound closure was monitored and photographed at 0 and $24 \mathrm{~h}$ using an inverted phase-contrast microscope (CKX41SF, Olympus, Tokyo, Japan). The distance of cell migration was measured based on the original location of the cells immediately after the cell layers were scratched. These experiments were repeated at least twice with similar results.

In vitro tube formation assay. Growth factor-reduced Matrigel (BD) was added to 96-well plates and polymerized for $30 \mathrm{~min}$ at $37^{\circ} \mathrm{C}$. The BAECs were starved in $0.5 \% \mathrm{FBS}$ in DMEM/low-glucose for $16 \mathrm{~h}$, seeded at $3 \times 10^{4}$ cells on the surface of the Matrigel, and incubated for 8-16 h with or without VEGF $(40 \mathrm{ng} / \mathrm{ml})$ or D-2HG $(250 \mu \mathrm{M})$ in DMEM/low-glucose containing $0.5 \%$ FBS. Morphological changes were observed under a microscope (CKX41SF, Olympus) and photographed at $\mathrm{x} 100$ magnification. The results are presented as the mean number of branching points.

Chick embryo chorioallantoic membrane (CAM) assay. Fertilized chicken eggs (CJ Corp., Seoul, Korea) were maintained in a humidified incubator (Eunjo Incubator Company, Pocheon, Korea) at $37^{\circ} \mathrm{C}$ for 3 days. CAM assay was performed as previously described (3). Briefly, on day 4.5, chemical-loaded Thermanox coverslips (Nunc, Rochester, NY, USA) were applied to the CAM surface. Two days later, a $20 \%$ fat emulsion (SMOFlipid, Fresenius Kabi Austria $\mathrm{GmbH}$, Hafnerstra, Austria) was injected beneath the CAM and observed under a stereomicroscope. Phorbol 12-myristate 13-acetate (PMA) was used as a positive control. Fifteen eggs per group were used in each experiment, and experiments were performed in triplicate.

Gelatin zymography. Supernatants from cell cultures were analyzed for gelatin degradation activity of matrix metalloproteinase (MMP) by sodium dodecyl sulfate-polyacrylamide gel electrophoresis (SDS-PAGE) under non-reducing conditions. Gelatin $(1 \mathrm{mg} / \mathrm{ml})$ was pre-polymerized on $10 \%$ polyacrylamide gels as a substrate. Electrophoresis was carried out at room temperature. The gels were washed with $2.5 \%$ Triton X-100 washing buffer twice, followed by incubation with a zymography reaction buffer at $37^{\circ} \mathrm{C}$ overnight. The samples were stained with Coomassie Blue (Thermo Fisher Scientific) for $10 \mathrm{~min}$ and dried at room temperature.

Whole-cell extract preparation and western blot analysis. Cell extract preparation and western blot analysis were performed as previously described (32). Briefly, the cells were lysed with PRO-PREP protein extraction solution (iNtRON Biotechnology, Seoul, Korea), and the lysates protein concentrations were measured using a Pierce BCA protein assay kit (Thermo Fisher Scientific). Proteins $(50 \mu \mathrm{g})$ were loaded and separated by $10 \%$ SDS-PAGE and transferred onto nitrocellulose membranes (Whatman Inc., Maidstone, UK). After blocking for $30 \mathrm{~min}$ with $5 \%$ skim milk at room temperature, the nitrocellulose membranes were incubated with primary antibodies for overnigh at $4^{\circ} \mathrm{C}$ and secondary antibodies for $1 \mathrm{~h}$ at room temperature. The immune complexes were detected using enhanced chemiluminescence reagents (34577; Thermo Fisher Scientific). Primary antibodies used for western blot analysis were as follows: HIF-1 $\alpha(1 / 500$; Cat. no. 610958; BD Biosciences, San Diego, CA, USA), IDH1 (1/1,000; Cat. no. 3997; Cell Signaling Technology, Danvers, MA, USA), IDH2 (1/1,000; Cat. no. ab131263; Abcam, Cambridge,UK),IDH2-172K (1/500; Cat.no.D-328-3; MBLCo. Ltd., Nagoya, Japan), phospho-VEGFR2 (1/500; Cat. no. 2478; Cell Signaling Technology), VEGFR2 (1/1,000; Cat. no. 2479; Cell Signaling Technology), phospho-ERK (1/1,000; Cat. no. 9101; Cell Signaling Technology), ERK (1/1,000; Cat. no. 9102; Cell Signaling Technology), phospho-FAK (1/1,000; Cat. no. sc-81493; Santa Cruz Biotechnology), FAK (1/1,000; Cat. no. ab40794; Abcam), phospho-AKT (1/1,000; Cat. no. 9271; Cell Signaling Technology), AKT (1/1,000; Cat.no. 4691; Cell Signaling Technology) and $\beta$-actin $(1 / 1,000$; sc-47778; Santa Cruz Biotechnology). HRP-linked secondary 
A

Mock IDH2-R172K
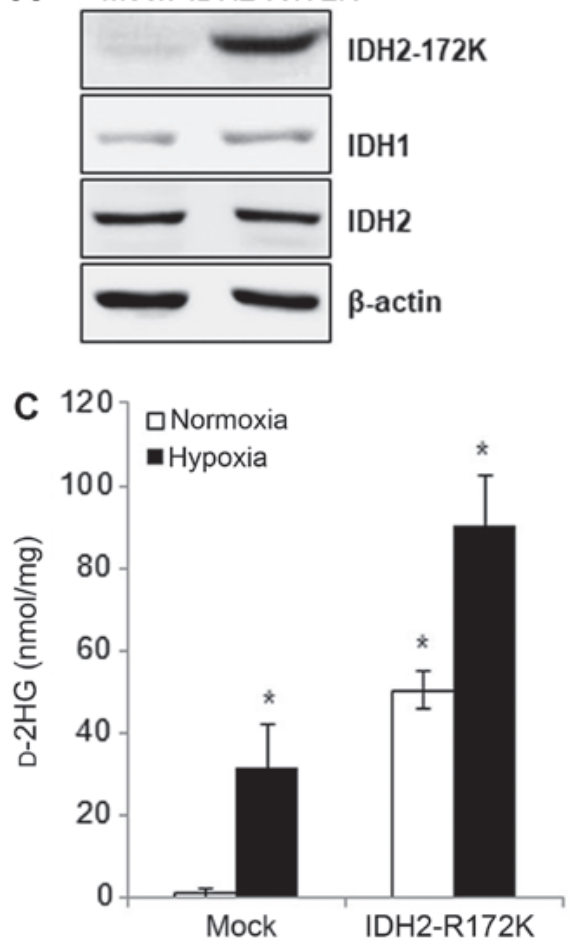

B<smiles>O=C(O)CCC(O)C(=O)O</smiles>

D-2HG

D

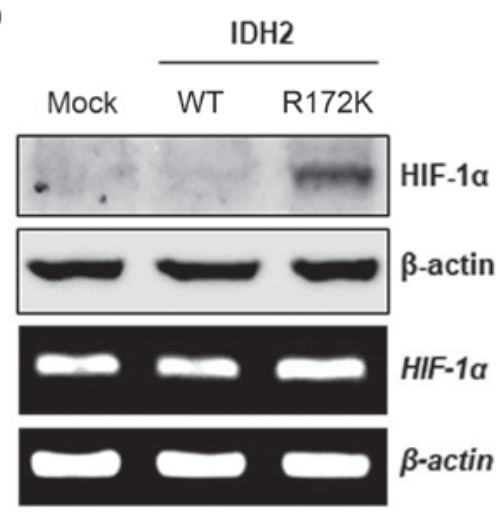

Figure 1.IDH2-R172K mutation increases D-2HG production.(A) 293 cells $\left(2.4 \times 10^{6}\right)$ were transfected with $8 \mu$ g pLenti6.2/V5 mock orpLenti6.2/V5-IDH2 (R172K) vector using Polyfect reagent. MDA-MB-231 cells were infected with viral supernatants after $48 \mathrm{~h}$ of transfection in the presence of polybrene (10 $\mu \mathrm{g} / \mathrm{ml})$ for $6 \mathrm{~h}$, and protein lysates were applied for western blot analysis of the indicated proteins. $\beta$-actin was used as a loading control. (B) Chemical structure of D-2HG. (C) Levels of D-2HG in cell lysates were analyzed by D-2HG assays. (D) After the HepG2 cells were infected with wild-type (WT) or R172K IDH2 lentiviral supernatant, HIF-1 $\alpha$ protein and mRNA levels were determined by western blot analysis or semi-quantitative RT-PCR. $\beta$-actin was used as an internal control. ${ }^{*} \mathrm{P}<0.05$ vs. mock under normoxia. D-2HG, D-2-hydroxyglutarate; HIF-1 $\alpha$, hypoxia-inducible factor $\alpha$.

antibodies were obtained from Cell Signaling Technology $(1 / 5,000 ;$ Cat. nos. 7076 and 7074).

RNA isolation and reverse transcription-polymerase chain reaction $(R T-P C R)$. Total RNA was extracted from IDH2-R172K mutant cells overexpressing HepG2 using TRIzol reagent (Invitrogen/Thermo Fisher Scientific) according to the manufacturer's instructions, and cDNA synthesis was carried out with ReverTra Ace qPCR Master Mix (Toyobo, Osaka, Japan). Semi-quantitative PCR was performed as previously described using AccuPower PCR premix (Bioneer, Daejeon, Korea). The PCR conditions were as follows: 30 cycles of denaturation $\left(94^{\circ} \mathrm{C} / 1 \mathrm{~min}\right)$, annealing $\left(60^{\circ} \mathrm{C} / 1 \mathrm{~min}\right)$, and extension $\left(72^{\circ} \mathrm{C} / 1 \mathrm{~min}\right)$, and final extension $\left(72^{\circ} \mathrm{C} / 10 \mathrm{~min}\right)$. The primers used for $H I F-1 \alpha$ were as follows: forward, 5'-CAGAAGATACAAGTAGCCTC-3' and reverse, 5'-GGCCCGGTGCAGCACCACCA-3'; and those for $\beta$-actin were as follows: forward, 5'-GACTACCTCATGAAGATC-3' and reverse, 5'-GATCCACATCTGCTGGAA-3'. PCR products were separated on $1.5 \%$ agarose gels in $1 \mathrm{X}$ TAE buffer, stained with ethidium bromide and visualized under UV light.

Statistical analysis. All data are expressed as the means \pm standard deviations (SD) from at least 3 samples. Statistical comparisons were determined by a Student's t-test using GraphPad Prism 5.04 (GraphPad Software, Inc., La Jolla, CA, USA). Comparisons among multiple groups were analyzed using one-way analysis of variance (ANOVA) with the Newman-Keuls post hoc test. Differences with $\mathrm{P}<0.05$ were considered statistically significant.

\section{Results}

$2 H G$ levels are increased by hypoxia and IDH2 mutations in breast cancer cells. We infected the MDA-MB-231 human breast cancer cells with lentiviral particles following transfection with IDH2-R172K mutant-lentiviral vector in 293T cells, and the overexpression of IDH2-R172K mutants was identified by western blot analysis using anti-IHD2-R172K antibodies (Fig. 1A). We then analyzed altered metabolites in MDA-MB-231 cancer cells due to hypoxia and IDH2 mutation using metabolite profiling. The analysis identified a total of 116 up- or downregulated compounds, which were involved in glycolysis; the PPP; the TCA cycle; the urea cycle; and polyamine, creatinine, purine, glutathione, nicotinamide, choline and amino acid metabolism, as annotated on the HMT metabolite database. Among these compounds, 28 metabolites, including $2 \mathrm{HG}$, a well-known metabolite in IDH2 mutants, were upregulated (Table I). Hypoxia increased 2HG levels by 4.1 -fold, whereas IDH2 mutation increased $2 \mathrm{HG}$ levels by 1.7 -fold. HMT metabolite analysis did not distinguish the D-form or L-form of $2 \mathrm{HG}$. As hypoxia usually increases L-2HG levels, the increase in $2 \mathrm{HG}$ levels by hypoxia may primarily involve L-2HG. Of note, many metabolites were overlapped under hypoxic conditions and IDH mutants, and the levels of many intermediate metabolites in glycolytic pathways, such as glucose-6-phosphate, fructose 1,6-diphosphate and 
Table I. Representative increased metabolites in hypoxic or IDH2R172K mutant MDA-MB-231 cells.

\begin{tabular}{|c|c|c|c|c|c|c|c|c|c|}
\hline Rank & Metabolites & Nomoxia & Hypoxia & Fold & Rank & Metabolites & Nomoxia & IDH2-R172K & Fold \\
\hline & 2-Hydroxyglutaric acid & 52 & 213 & 4.1 & & 2-Hydroxyglutaric acid & 52 & 86 & 1.7 \\
\hline 1 & Fructose 6-phosphate & 16 & 23 & 85.0 & 1 & Glucose 1-phosphate & N.D. & 27 & 27.0 \\
\hline 2 & $\mathrm{~N}$-Carbamoylaspartic acid & 24 & 439 & 18.4 & 2 & Succinic acid & 58 & 343 & 6.0 \\
\hline 3 & Glucose 1-phosphate & N.D. & 9.9 & 9.9 & 3 & Uric acid & 5.7 & 33 & 5.8 \\
\hline 4 & Inosine monophosphate & 4.5 & 31 & 6.8 & 4 & Citrulline & 327 & 1,405 & 4.3 \\
\hline 5 & Glycerol 3-phosphate & 59 & 143 & 2.4 & 5 & 2-Phosphoglyceric acid & 8.7 & 36 & 4.2 \\
\hline 6 & Guanosine monophosphate & 5.6 & 13 & 2.3 & 6 & Lactic acid & 8,669 & 31,288 & 3.6 \\
\hline 7 & Fructose 1,6-diphosphate & 440 & 811 & 1.8 & 7 & 3-Phosphoglyceric acid & 139 & 454 & 3.3 \\
\hline 8 & Ornithine & 103 & 187 & 1.8 & 8 & Fructose 6-phosphate & 16 & 52 & 3.2 \\
\hline 9 & Lysine & 153 & 262 & 1.7 & 9 & Glucose 6-phosphate & 74 & 225 & 3.0 \\
\hline 10 & Glutamine & 853 & 1,343 & 1.6 & 10 & Ornithine & 103 & 289 & 2.8 \\
\hline 11 & Guanosine 5'-phosphate & 20 & 30 & 1.5 & 11 & Phosphoenolpyruvic acid & 26 & 69 & 2.7 \\
\hline 12 & Succinic acid & 58 & 86 & 1.5 & 12 & Alanine & 242 & 613 & 2.5 \\
\hline 13 & Folic acid & 1.3 & 2.0 & 1.5 & 13 & Guanosine monophosphate & 5.6 & 12 & 2.1 \\
\hline 14 & Phenylalanine & 87 & 127 & 1.5 & 14 & Lysine & 153 & 301 & 2.0 \\
\hline 15 & 3-Phosphoglyceric acid & 139 & 191 & 1.4 & 15 & Guanosine 5'-phosphate & 20 & 37 & 1.9 \\
\hline 16 & Creatinine & 16 & 22 & 1.4 & 16 & Phenylalanine & 87 & 157 & 1.8 \\
\hline 17 & Histidine & 111 & 148 & 1.3 & 17 & Glycerol 3-phosphate & 59 & 96 & 1.6 \\
\hline 18 & Lactic acid & 8,669 & 11,418 & 1.3 & 18 & Inosine monophosphate & 4.5 & 7.2 & 1.6 \\
\hline 19 & Phosphoenolpyruvic acid & 26 & 34 & 1.3 & 19 & Histidine & 111 & 165 & 1.5 \\
\hline 20 & GTP & 530 & 691 & 1.3 & 20 & Folic acid & 1.3 & 1.9 & 1.5 \\
\hline 21 & 2-Phosphoglyceric acid & 8.7 & 11 & 1.3 & 21 & Fructose 1,6-diphosphate & 440 & 638 & 1.5 \\
\hline 22 & Citrulline & 327 & 381 & 1.2 & 22 & Acetyl CoA & 9.3 & 13 & 1.4 \\
\hline 23 & Acetyl CoA & 9.3 & 11 & 1.1 & 23 & Creatinine & 16 & 21 & 1.3 \\
\hline 24 & Uric acid & 5.7 & 6.5 & 1.1 & 24 & Guanosine 5'-triphosphate & 530 & 673 & 1.3 \\
\hline 25 & Alanine & 242 & 272 & 1.1 & 25 & $\mathrm{~N}$-Carbamoylaspartic acid & 24 & 28 & 1.2 \\
\hline 26 & Glucose 6-phosphate & 74 & 80 & 1.1 & 26 & Glutamine & 853 & 1,003 & 1.2 \\
\hline 27 & Ribulose 5-phosphate & 32 & 33 & 1.1 & 27 & Ribulose 5-phosphate & 32 & 36 & 1.1 \\
\hline
\end{tabular}

Table II. Representative decreased metabolites in hypoxic or IDH2R172K mutants MDA-MB-231 cells.

\begin{tabular}{|c|c|c|c|c|c|c|c|c|c|}
\hline Rank & Metabolites & Nomoxia & Hypoxia & Fold & Rank & Metabolites & Nomoxia & IDH2-R172K & Fold \\
\hline & 2-Hydroxyglutaric acid & 52 & 213 & 1 & & 2-Hydroxyglutaric acid & 52 & 86 & 1 \\
\hline 1 & Glutathione (GSH) & 5,494 & 2,731 & 2.0 & 1 & Glutathione (GSH) & 5,494 & 205 & 26.9 \\
\hline 2 & Putrescine & 83 & 44 & 1.9 & 2 & Putrescine & 83 & 19 & 4.3 \\
\hline 3 & HMG CoA & 2.4 & 2.1 & 1.1 & 3 & HMG CoA & 2.4 & 2.0 & 1.2 \\
\hline
\end{tabular}

lactic acids, were increased in the mutants (Table I). Some metabolites involved in creatinine synthesis and purine metabolism were also upregulated. Notably, hypoxia and IDH 2 mutation resulted in the downregulation of glutathione, $\beta$-hydroxy $\beta$-methylglutaryl-CoA and putrescine. Among these downregulated metabolites, glutathione is the main substrate affecting cellular antioxidant potential (33) (Table II), suggesting that IDH2 mutation and hypoxia suppress antioxidant potential.

To determine whether the D-form of $2 \mathrm{HG}$ was increased, we evaluated the amount of D-2HG in the MDA-MB-231 cells exposed to hypoxia or harboring the IDH2-R172K mutation. Compared with the normoxic controls, hypoxia significantly increased the D-2HG levels. The IDH2-R172K mutants also exhibited significant increases in intracellular D-2HG contents (Fig. 1C). Koivunen et al (2012) reported that D-2HG increased EGLN activity, leading to diminished HIF levels (29). However, in this study, we observed that HIF-1 $\alpha$ protein expression was increased, while its mRNA level was not altered in the IDH2-R172K mutant overexpressing HepG2 human liver cancer cells (Fig. 1D), suggesting that HIF-1 $\alpha$ is stabilized by the D-2HG same as the L-2HG in cancer cells. 

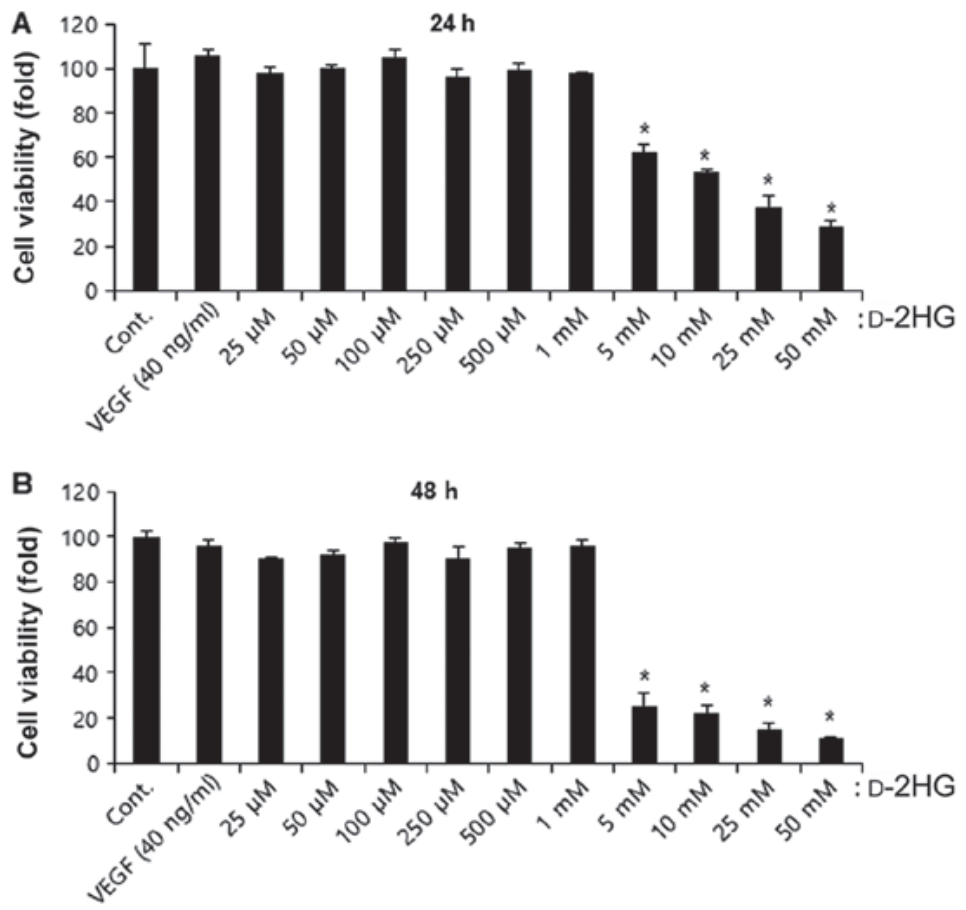

Figure 2. Cytotoxicity of D-2HG in BAECs. (A and B) BAECs were treated with various concentrations of D-2HG ( $25 \mu \mathrm{M}$ to $50 \mathrm{mM})$ for $24 \mathrm{~h}$ (A) or $48 \mathrm{~h}(\mathrm{~B})$. Cell viability was measured by CCK- 8 assays. VEGF $(40 \mathrm{ng} / \mathrm{ml})$ was used as a positive control. $\mathrm{P}<0.05$ versus the control. BAECs, bovine aortic endothelial cells; D-2HG, D-2-hydroxyglutarate; VEGF, vascular endothelial growth factor.
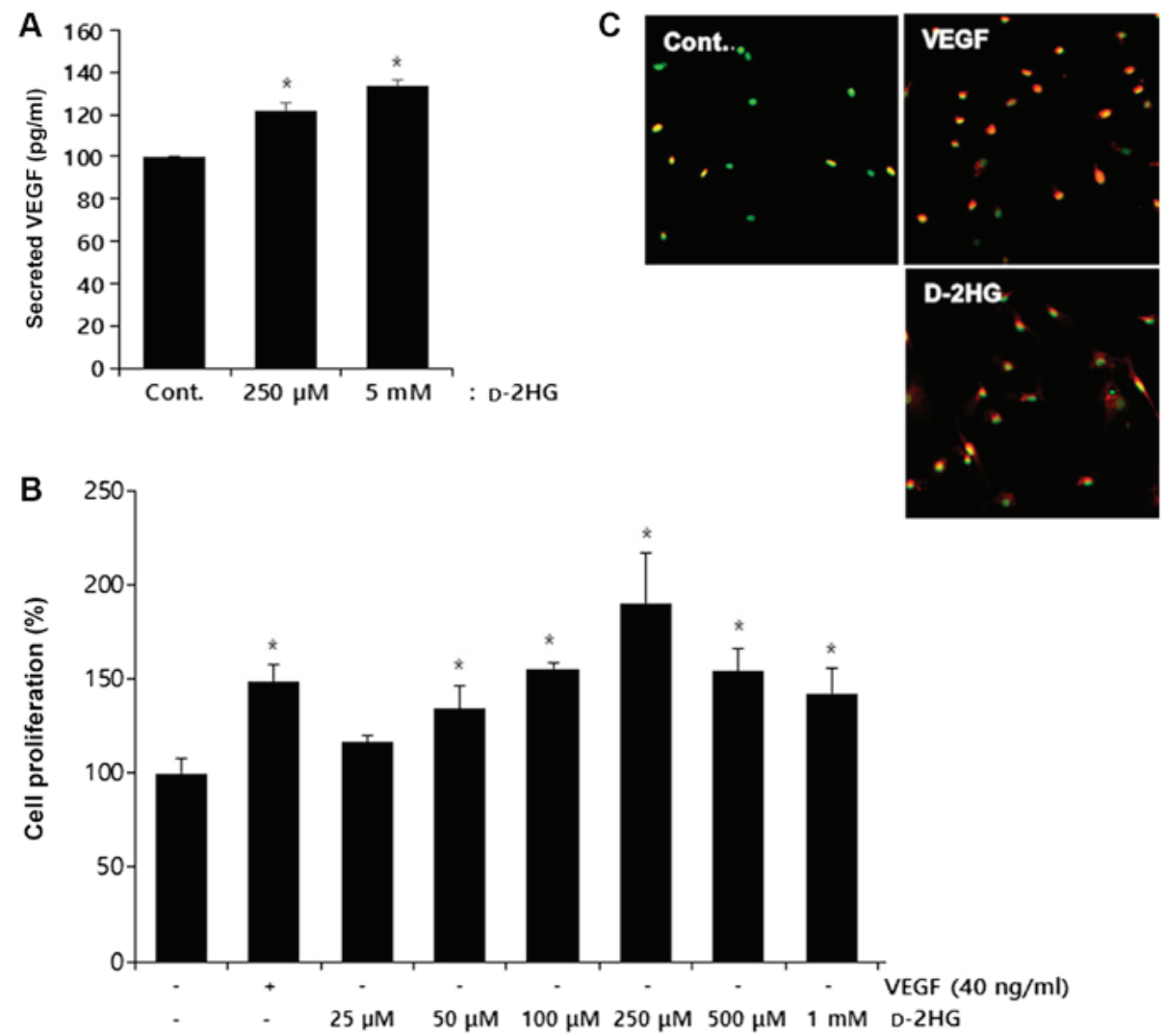

Figure 3. D-2HG increases VEGF secretion and the proliferation of BAECs. (A) A549 cells were starved for $16 \mathrm{~h}$ in $0.5 \%$ FBS-containing medium, treated with D-2HG ( $250 \mu \mathrm{M}$ and $5 \mathrm{mM}$ ), collected and analyzed for VEGF protein levels using a VEGF ELISA kit. "P $<0.05$ versus the control. (B) BAECs were seeded at $2 \times 10^{3}$ cells/well in 96-well culture plates, then incubated for $24 \mathrm{~h}$, and starved in $0.5 \% \mathrm{FBS}$ in DMEM/low glucose for $16 \mathrm{~h}$. The cells were treated with D-2HG at the indicated concentrations or VEGF $(40 \mathrm{ng} / \mathrm{ml})$ in $0.5 \%$ FBS in DMEM/low glucose. Cell proliferation was assayed using a BrdU kit, and the percentage relative to the control was calculated. "P $<0.05$ versus the control. (C) BAECs were starved with $0.5 \%$ FBS in DMEM/low glucose for $16 \mathrm{~h}$, incubated with various concentrations of D-2HG or VEGF ( $40 \mathrm{ng} / \mathrm{ml}$ ) for $24 \mathrm{~h}$ in DMEM/low glucose containing 0.5\% FBS, fixed with 4\% paraformaldehyde solution, and permeabilized with $0.1 \%$ Triton X-100/PBS. Fixed cells were blocked with 1\% BSA in PBS and incubated with anti-Ki67 antibodies. Green color indicates Hoechst dye staining the nucleus and red color indicates Ki67-stained cells. BAECs, bovine aortic endothelial cells; D-2HG, D-2-hydroxyglutarate; VEGF, vascular endothelial growth factor. 
A

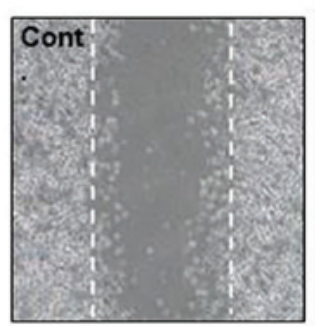

B
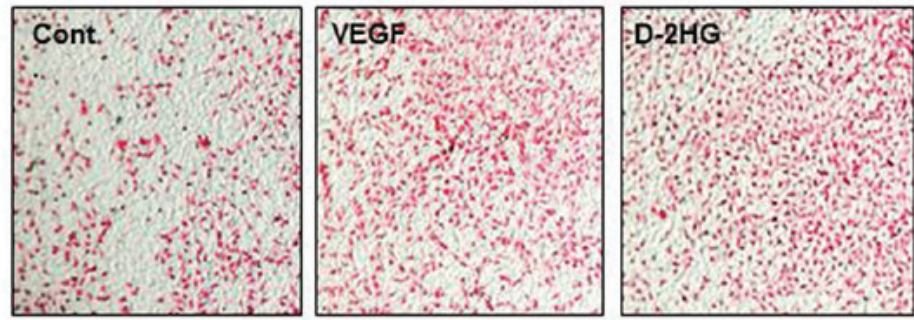

C
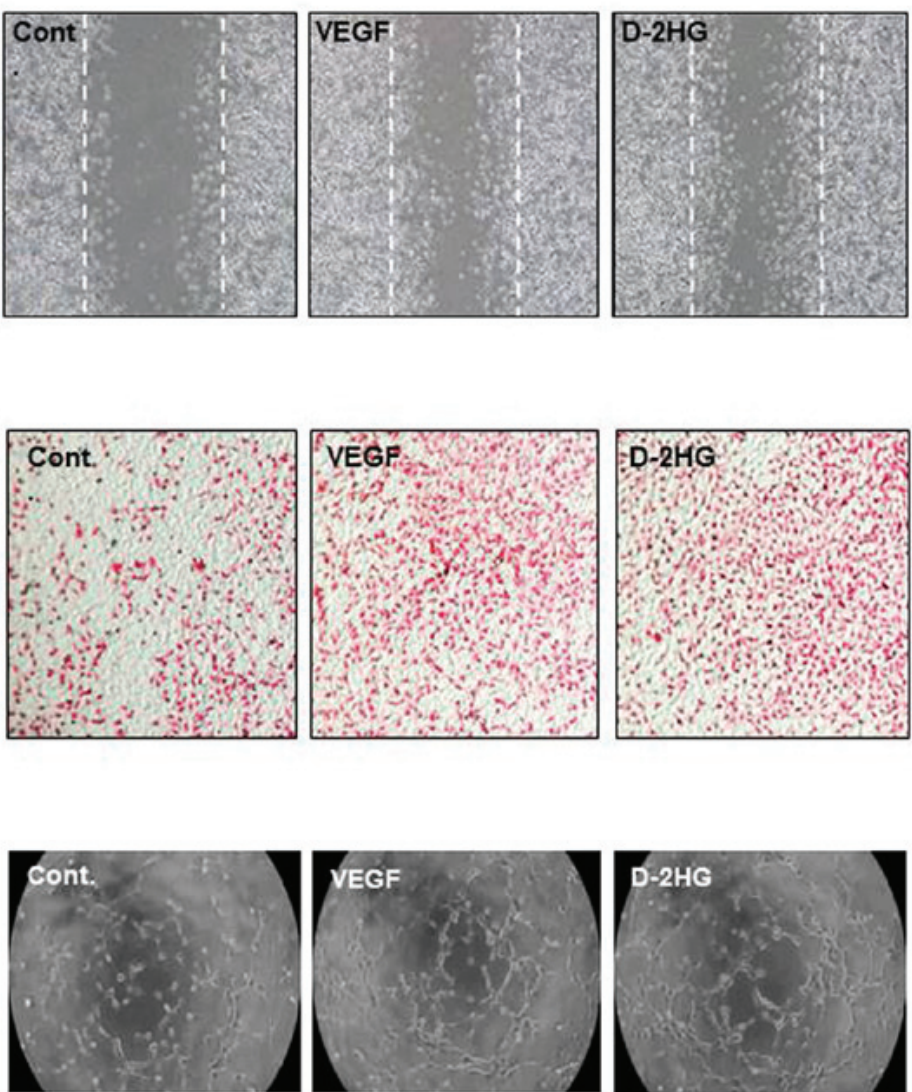
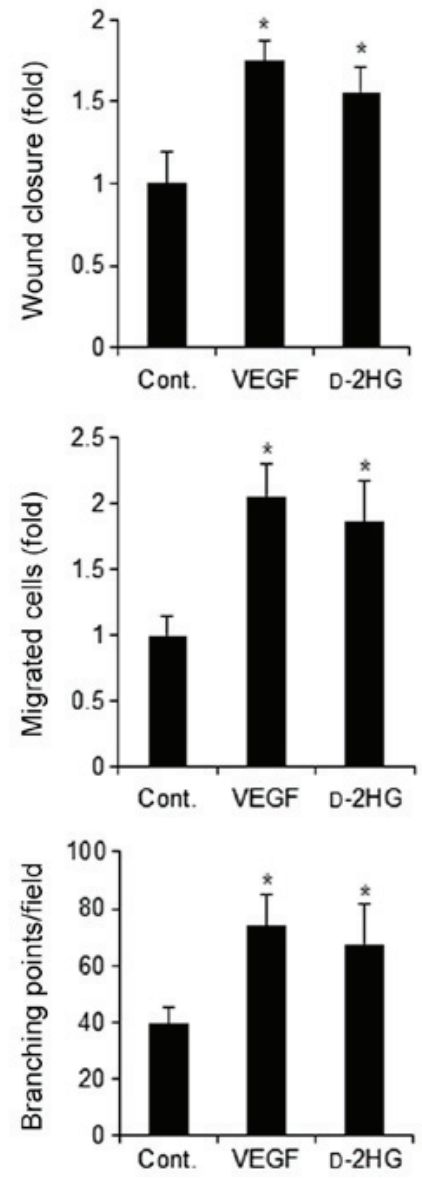

Figure 4. D-2HG increased migration and tube formation ability in BAECs. (A) BAECs (90\% confluence) were starved with 0.5\% FBS in DMEM/low glucose for $16 \mathrm{~h}$ and treated with mitomycin $\mathrm{C}(1 \mu \mathrm{g} / \mathrm{ml})$ for $1 \mathrm{~h}$. The cells were scratched with a 1-ml micropipette tip and incubated in starvation medium with VEGF $(40 \mathrm{ng} / \mathrm{ml})$ or $\mathrm{D}-2 \mathrm{HG}(250 \mu \mathrm{M})$. Wound closure from the original location was monitored and graphed. * $\mathrm{P}<0.05$ versus the control. (B) Transwell migration assays were performed in 24-Transwell plates $(6.5 \mathrm{~mm}$ diameter, $8 \mu \mathrm{m}$ pore size membrane). BAECs were seeded in the upper chamber, and VEGF (40 ng/ml) and D-2HG $(250 \mu \mathrm{M})$ were added to the lower chambers for $24 \mathrm{~h}$. Migrated cells were fixed with $100 \%$ methanol, stained with hematoxylin and eosin, and counted. ${ }^{*} \mathrm{P}<0.05$ versus the control. (C) BAECs were starved in $0.5 \%$ FBS in DMEM/low glucose for $16 \mathrm{~h}$, seeded ( $3 \times 10^{4}$ cells) on the surface of the Matrigel, and incubated for $8-16 \mathrm{~h}$ with or without VEGF (40 ng/ml) or D-2HG (250 $\mu \mathrm{M})$ in DMEM/low glucose containing $0.5 \%$ FBS. Morphological changes were observed under a microscope and photographed at x100 magnification. The results are presented as the mean number of branching points. BAECs, bovine aortic endothelial cells; D-2HG, D-2-hydroxyglutarate; VEGF, vascular endothelial growth factor.

A

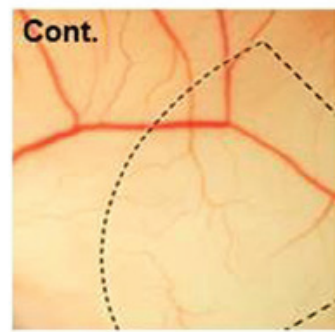

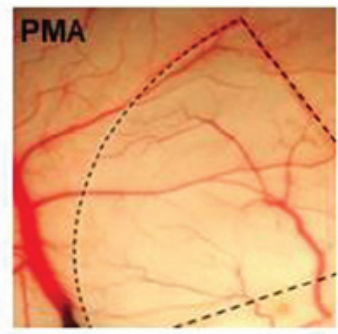

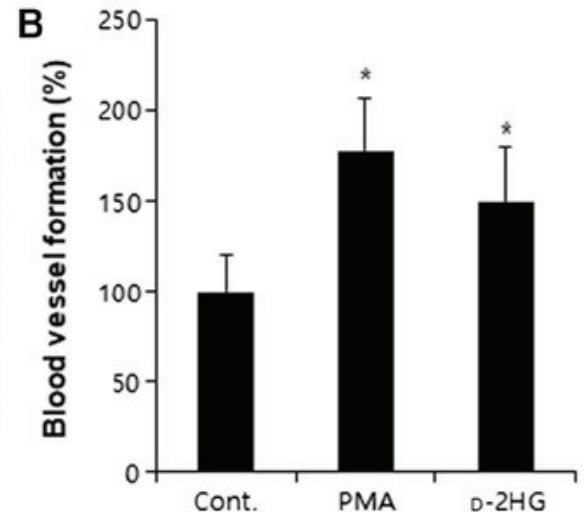

Figure 5. D-2HG increased angiogenic activity ex vivo in chick CAM assays. (A) D-2HG (250 2H)-loaded Thermanox coverslips (dotted quarter circle) were applied to the CAM surface on fertilized chicken eggs (day 4.5), incubated for 48 h, and observed under a stereomicroscope. Phorbol 12-myristate 13-acetate (PMA) was used as a positive control. (B) The number of eggs showing positive angiogenic responses was counted and graphed (n=15/group, triplicate). ${ }^{*} \mathrm{P}<0.05$ versus the control.

D-2HG induces endothelial cell proliferation. To determine the non-toxic concentrations of $\mathrm{D}-2 \mathrm{HG}$ in endothelial cells, we examined cell viability using CCK- 8 assays in the BAECs.
From the concentration of $25 \mu \mathrm{M}$ to $1 \mathrm{mM}$, D-2HG was not toxic to the endothelial cells; however, at concentrations $>5 \mathrm{mM}$, cytotoxicity increased significantly at both 24 and 

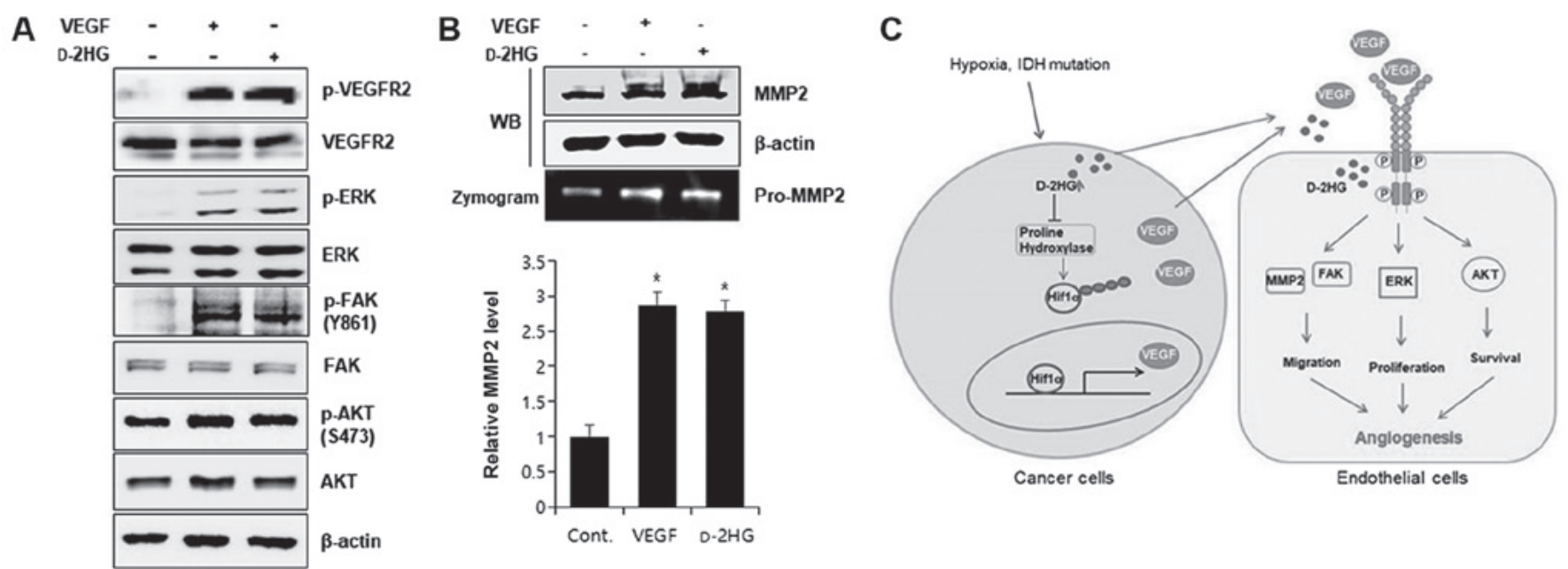

Figure 6. D-2HG induces VEGFR2 signaling pathway activation and MMP2 activity. (A) BAECs were treated with VEGF (40 ng/ml) or D-2HG (250 $\mu \mathrm{M})$ for $10 \mathrm{~min}$, and protein lysates was obtained for western blot analysis. (B) Western blot analysis and gelatin zymography analyses for MMP2 and pro-MMP2, respectively, were performed with medium obtained from the same samples as described in (A). The relative expression pattern of MMP2 was quantified and graphed below the gel images. ${ }^{*} \mathrm{P}<0.05$ versus the control. (C) Schematic summary of the mechanism through which D-2HG enhances angiogenesis.

48 h (Fig. 2). Thus, we used concentrations $<1 \mathrm{mM}$ to identify the angiogenic activity.

As D-2HG inhibits proline hydroxylases (25), we hypothesized that this metabolite may also increase VEGF protein levels via the inhibition of HIF-1 degradation. To confirm this hypothesis, we evaluated the secretion of VEGF in serum-starved medium following treatment of the cancer cells with D-2HG. We found that D-2HG increased VEGF secretion from the cells (Fig. 3A). To determine whether D-2HG affecs endothelial cell proliferation to modulate angiogenesis (5), we performed BrdU cell proliferation assays and immunostaining for Ki67 in the endothelial cells. D-2HG increased endothelial cell proliferation in a concentration-dependent manner from the concentrations of 25 to $250 \mu \mathrm{M}$, but did not exert concentration-dependent effects at the concentrations of $500 \mu \mathrm{M}$ and $1 \mathrm{mM}$, although increased proliferation was still observed (Fig. 3B). Therefore, we selected the concentrations of $250 \mu \mathrm{M}$ D-2HG to reveal the maximum effects on angiogenic activity for the subsequent experiments. Immunostaining of the proliferating cells with anti-Ki67 antibodies indicated that the increase in cell proliferation induced by $\mathrm{D}-2 \mathrm{HG}(250 \mu \mathrm{M})$ was similar to that induced by VEGF (40 ng/ml; Fig. 3C).

D-2HG induces endothelial cell migration and tube formation capacity. As endothelial cell migration is a key step in angiogenesis (5), in this study, we performed both wound healing motility and Transwell migration assays. When wound closure was monitored for $24 \mathrm{~h}, \mathrm{D}-2 \mathrm{HG}$ increased the cell migratory capacity, similar to the effects observed with VEGF (Fig. 4A). Wound closure was increased to 1.5 fold by D-2HG treatment compared with the control cells. The cell migratory capacity induced by $\mathrm{D}-2 \mathrm{HG}$ examined by Transwell assay was also significantly increased by approximately 2 -fold, similar to that induced by VEGF (Fig. 4B).

The reorganization of angiogenesis is involved in tube formation (5). In this study, to determine the ability of $\mathrm{D}-2 \mathrm{HG}$ to induce the formation of capillary-like structures, we performed tube formation assays using the endothelial cells.
D-2HG increased the formation of capillary-like structures, as did VEGF (Fig. 4C). The number of branching points was significantly increased by VEGF and D-2HG to 1.6- and 2-fold that of the control, respectively (Fig. 4C).

D-2HG induces the formation of functional new blood vessels in CAMs ex vivo. To confirm the in vitro angiogenic activity of $\mathrm{D}-2 \mathrm{HG}$, we performed ex vivo angiogenesis assays. $\mathrm{D}-2 \mathrm{HG}$ induced the formation of neovessels from the large vessels in the CAM region, as shown in Fig. 5A. Networks between new vessels were very complex, and vessel branching points were increased in the $\mathrm{D}-2 \mathrm{HG}$-treated CAMs, similar to those in the PMA-treated CAMs (Fig. 5B). Eggs exhibiting $>30 \%$ neovessel formation were considered positive, and the percentage of positive eggs was calculated. The numbers of angiogenic CAMs were significantly increased by treatment with D-2HG compared with that in the controls (Fig. 5B).

D-2HG activates VEGFR2 signaling and matrix metalloproteinase $(M M P) 2$ activity. VEGF/VEGFR2, the most prominent ligand-receptor complex in the VEGF system, induces endothelial cell proliferation, migration, survival, and new vessel formation associated with angiogenesis (34). VEGFR2 activation promotes the expression of downstream signaling molecules, such as AKT, p42/44 extracellular signal-regulated kinase (ERK) and $\mathrm{p} 38$ mitogen-activated protein kinase (MAPK), and focal adhesion kinase (FAK) (34). In this study, we found that $\mathrm{D}-2 \mathrm{HG}$ clearly increased the phosphorylation of VEGFR2 (Fig. 6A), suggesting that VEGFR2 expression and activation were induced by $\mathrm{D}-2 \mathrm{HG}$. The activation of $\mathrm{p} 42 / 44$ ERK, AKT and FAK was observed following treatment with $\mathrm{D}-2 \mathrm{HG}$, suggesting that $\mathrm{D}-2 \mathrm{HG}$ increased angiogenic activity through the activation of VEGFR2 signaling.

MMP is activated by growth factor signaling, and its activation is essential for matrix degradation and cell migration and to release growth factors, such as VEGF, from the matrix (35). Of note, D-2HG significantly enhanced MMP2 activation, as observed by gelatin zymography and western 
blot analysis (Fig. 6B) to the same level induced by VEGF, suggesting that $\mathrm{D}-2 \mathrm{HG}$ increased angiogenic activity via the activation of MMP2. Taken together, these results indicated that $\mathrm{D}-2 \mathrm{HG}$ increased angiogenic capacity via VEGF secretion and activated VEGFR2 signaling, including FAK, in vascular endothelial cells.

\section{Discussion}

In this study, we demonstrated that the $\mathrm{D}$-form of $\mathrm{HG}$, an oncometabolite, increased angiogenesis. D-2HG is produced by mutated IDH enzymes found in a subsets of leukemias and brain tumors (27). Additionally, D-2HG levels are increased through glutamine anaplerosis, even in the absence of IDH mutation (28). In this study, in IDH2R172K mutant human breast cancer cells, $2 \mathrm{HG}$ levels and metabolites involved in the glycolytic pathway were increased.

Standard methods for measuring metabolites by gas chromatography mass spectrometry do not distinguish enantiomeric species; thus, total $2 \mathrm{HG}$ measured in most assays includes both $\mathrm{D}-2 \mathrm{HG}$ and L-2HG. In this study, we demonstrated the that $\mathrm{D}-2 \mathrm{HG}$ contents were increased in the context of hypoxia and in IDH 2 mutant cells. D-2HG exhibited cytotoxicity at concentrations $>5 \mathrm{mM}$ in vascular endothelial cells; this concentration was lower than that used in other reports, i.e., $50 \mathrm{mM}$, for the analysis of metabolites in cancer cells (14), suggesting that vascular endothelial cells are more susceptible to higher concentrations of $\mathrm{D}-2 \mathrm{HG}$. The serum levels of $\mathrm{D}-2 \mathrm{HG}$ in patients with IDH1/2-mutated biliary tract cancer have been shown to be approximately $11 \mu \mathrm{M}$ (median value) (36). Therefore, $250 \mu \mathrm{M}$ D-2HG was sufficient to observe the angiogenic activity in endothelial cells.

The oncometabolite D-2HG increased endothelial cell proliferation, migration and tube formation, and the angiogenic activity of this compound was similar to that of VEGF. In addition, VEGFR2 activation was observed following treatment with $\mathrm{D}-2 \mathrm{HG}$. D-2HG increased the activation of VEGFR2 signaling. Phosphatidylinositol 3-kinase (PI3K)/AKT signaling increases the survival of endothelial cells, whereas the MAPK kinase/p42/44 ERK pathway is involved in endothelial cell proliferation. The activation of FAK increases the migration activity of endothelial cells. In addition to FAK activation, MMP2 increases matrix degradation and facilitates cell migration $(35,37)$. The functional activation of PI3K, ERK and FAK by D-2HG may increase angiogenic activity. MMP2 activation also increases the levels of VEGF released from the matrix, promoting the binding of VEGF to its receptors (35). Therefore, D-2HG increases both VEGF availability to bind with VEGFR2 and enhances cell migration by modulation of MMP2 activity. However, the mechanisms through which D-2HG regulates MMP2 activity are still unclear.

VEGF expression can be enhanced by $\mathrm{D}-2 \mathrm{HG}$ through the activation of the ERK/MAPK pathway to increase the expression of activating protein (AP)-1, and AP-1 then increases $V E G F$ gene transcription. This event must occur very early as treatment with D-2HG increased MAPK expression, including p42/44 ERK expression, within $10 \mathrm{~min}$. Since it has been reported that hypoxia increases the formation of L-2HG independent of the IDH mutation, and elevated $\mathrm{L}-2 \mathrm{HG}$ stabilizes HIF-1 $\alpha$ (30), in the presence of both metabolites the angiogenic activity will be further increased. Therefore, further studies are required to investigate whether $\mathrm{L}-2 \mathrm{HG}$ induces angiogenic activity and to determine the differences between $\mathrm{L}-2 \mathrm{HG}$ and $\mathrm{D}-2 \mathrm{HG}$.

Metabolites altered by IDH2R172K and IDH1R132H mutations and by high-dose $2 \mathrm{HG}(30 \mathrm{mM})$ treatment in glioma cells result in the elevation of numerous free amino acids, lipid precursors, such as glycerol-phosphate, and the depletion of TCA cycle intermediates, such as citrate; however, intermediates related to the glycolytic pathway were not altered (14). In this study, increased metabolites in IDH2R172K mutant cells overlapped with those induced by hypoxic stress conditions in breast cancer cells, including 2HG. We found that lipid precursors, such as glycerol-3 phosphate, and many metabolites related to the glycolytic pathway, such as glucose-6-phosphate, fructose-6-phosphate and lactic acid, were elevated under hypoxic conditions and in IDH2R172K mutant cells. Moreover, hypoxia and IDH2R172K mutation also increased lipid precursors and numerous free amino acids, consistent with previous findings (14), suggesting that IDH2R172K mutation preferentially altered the metabolic machinery, such as glycolysis and the PPP, to yield high levels of energy, similar to hypoxia $(2,14)$. The most markedly decreased metabolite was the reduced form of glutathione both in hypoxic conditions and in IDH2R172K mutant cells. As the reduced form of glutathione is essential for scavenging oxidative stress by providing electrons (33), the IDH2R172K mutation may increase oxidative stress, as previously reported (38).

The D-2HG-induced angiogenic activity can be caused by alterations in various metabolites as $2 \mathrm{HG}$ increases the levels of numerous metabolites in glioma cells (14). In this study, lactate levels were increased by hypoxia, and we found that as mutations may play a role in increasing $\mathrm{D}-2 \mathrm{HG}$-dependent angiogenesis because lactate enhances hypoxia-induced responses, including angiogenesis, independent of HIF via the N-Myc downstream regulated gene-mediated ERK pathway (39). Inhibition of glycolysis suppresses pathological angiogenesis (40), suggesting that increased D-2HG and glycolytic metabolites cooperatively activate angiogenesis in tumors. D-2HG treatment induced VEGFR2 activation and downstream signaling. However, it is unclear as to whether VEGFR2 and MMP2 levels are induced by $\mathrm{D}-2 \mathrm{HG}$ in endothelial cells. It is possible that tge induction of VEGFR2 and MMP2 by D-2HG increases the secretion or expression of VEGF transcription in endothelial cells and VEGF also increased the transcription of these targets. It is also possible that an epigenetic mechanism, such as increased histone methylation of $V E G F R 2$ or $M M P 2$ gene promoters, may be involved as $\mathrm{D}-2 \mathrm{HG}$ inhibits histone demethylases as a gene inhibition mark (41). Collectively, these findings demonstrated that $\mathrm{D}-2 \mathrm{HG}$ increased VEGF secretion in cancer cells, but increased VEGFR2 activity and downstream signaling in endothelial cells. Therefore, further studies are warranted to determine whether VEGF is secreted in endothelial cells to induce autocrine regulation and to determine the mechanisms through which D-2HG activates VEGFR2 and downstream kinases.

The discovery of the IDH1/2 mutation has led to novel therapies for the restoration of normal IDH1/2 function 
or blockage of the production or downstream effects of D-2HG (24). AGI-5198 and AGI-6780 are selective inhibitors of the mutant IDH1 and IDH2 enzymes, respectively. They normalize $2 \mathrm{HG}$, reverse histone and DNA methylation and induce the differentiation of TF-1 erythroleukemia cells, as well as primary human acute myelogenous leukemia (AML) cells with IDH1/2 mutations (13). As IDH1/2 mutations are frequently reported in hematologic cancers and glioma, clinical trials have been conducted to treat the patients with these IDH1/2 mutations (24). Therefore, targeting IDH1/2 mutations has the advantage of developing specific therapies to treat specific types of cancer only harboring IDH1/2 mutations (24).

By contrast, the targeting of VEGFR2 signaling pathway is focused on the anti-angiogenic activity. Clinically, the development of antibodies against VEGF and kinase inhibitors targeting VEGFR2 is effective in modulating pathological angiogenesis in diseases characterized by abnormal angiogenesis, such as diabetic retinopathy and cancer (42). However, the anti-VEGF signaling strategy can enhance active angiogenesis recurrence by the increased HIF-1 $\alpha$ owing to hypoxia (43). In addition, tge targeting of VEGFR2 downstream signaling pathway can be competing with pro-angiogenic therapeutic strategies, such as wound healing (44).

VEGF can stimulate vasculogenesis in tumors, as well as normal physiology by recruiting bone marrow-derived hematopoietic progenitor cells (HPCs) and endothelial progenitor cells (EPCs) $(45,46)$. VEGF can increase the expression of nitric oxide (NO), prostacyclins and other soluble mediators that lead to vasodilation (47). Therefore, VEGF targeted therapy will cause vascular constriction, as well as the inhibition of physiological angiogenesis.

In conclusion, in this study, we provided insight into the effects of D-2HG on angiogenesis in cancer cells and demonstrated, for the first time, at least to the best of our knowledge, that this molecule induced angiogenesis and may be a good candidate for anti-angiogenic therapy. The findings of this study suggest that enhancing our understanding of cancer metabolic profiles and the functions of metabolites in cancer progression, such as angiogenesis, may provide a good foundation for the development of novel therapeutic agents in cancer research. Therefore, the appropriate utilization of metabolic inhibitors could be an effective clinical strategy.

\section{Acknowledgements}

The authors would like to thank Dr Hai Yan (Duke University) for kindly providing the pLenti6.2/V5 or pLenti6.2/V5-IDH2 (R172K) plasmids.

\section{Funding}

This study was supported by the Korean government (grant nos. NRF-2017R1A2B3002227 and NRF-2013R1A2A2 A01068868).

\section{Availability of data and materials}

The datasets used and/or analyzed during the current study are available from the corresponding author on reasonable request.

\section{Authors' contributions}

JS and SHY performed and analyzed the data from culture studies, molecular works and in vitro as well as in vivo angiogenic assay. SHL performed western blot analysis. JHJ synthesized and provided the many chemicals for the preliminary experiments and the conception of the study. YML initiated the study, supervised the experiments, and the analyzed data and wrote the manuscript. All authors read and approved the final manuscript.

\section{Ethics approval and consent to participate}

Not applicable.

\section{Patient consent for publication}

Not applicable.

\section{Competing interests}

The authors declare that they have no competing interests.

\section{References}

1. McKeown SR: Defining normoxia, physoxia and hypoxia in tumours-implications for treatment response. Br J Radiol 87: 20130676, 2014.

2. Bertout JA, Patel SA and Simon MC: The impact of $\mathrm{O}_{2}$ availability on human cancer. Nat Rev Cancer 8: 967-975, 2008.

3. Seok JK, Lee SH, Kim MJ and Lee YM: MicroRNA-382 induced by HIF- $1 \alpha$ is an angiogenic miR targeting the tumor suppressor phosphatase and tensin homolog. Nucleic Acids Res 42: 8062-8072, 2014.

4. Folkman J: Role of angiogenesis in tumor growth and metastasis. Semin Oncol 29 (Suppl 16): S15-S18, 2002.

5. Ferrara N and Kerbel RS: Angiogenesis as a therapeutic target. Nature 438: 967-974, 2005.

6. Vander Heiden MG, Cantley LC and Thompson CB: Understanding the Warburg effect: The metabolic requirements of cell proliferation. Science 324: 1029-1033, 2009.

7. Warburg O: P.K., Negelein E: The metabolism of tumors. Biochem Z 152: 319-344, 1924 (In German).

8. Losman JA and Kaelin WG Jr: What a difference a hydroxyl makes: Mutant IDH, (R)-2-hydroxyglutarate, and cancer. Genes Dev 27: 836-852, 2013.

9. Warburg O: On the origin of cancer cells. Science 123: 309-314, 1956.

10. Cairns RA, Harris IS and Mak TW: Regulation of cancer cell metabolism. Nat Rev Cancer 11: 85-95, 2011.

11. Raimundo N, Baysal BE and Shadel GS: Revisiting the TCA cycle: Signaling to tumor formation. Trends Mol Med 17: 641-649, 2011.

12. Wise DR, Ward PS, Shay JE, Cross JR, Gruber JJ, Sachdeva UM, Platt JM, DeMatteo RG, Simon MC and Thompson CB: Hypoxia promotes isocitrate dehydrogenase-dependent carboxylation of $\alpha$-ketoglutarate to citrate to support cell growth and viability. Proc Natl Acad Sci USA 108: 19611-19616, 2011.

13. Zhang C, Moore LM, Li X, Yung WK and Zhang W: IDH1/2 mutations target a key hallmark of cancer by deregulating cellular metabolism in glioma. Neuro-oncol 15: 1114-1126, 2013.

14. Reitman ZJ and Yan H: Isocitrate dehydrogenase 1 and 2 mutations in cancer: Alterations at a crossroads of cellular metabolism. J Natl Cancer Inst 102: 932-941, 2010.

15. Parsons DW, Jones S, Zhang X, Lin JC, Leary RJ, Angenendt P, Mankoo P, Carter H, Siu IM, Gallia GL, et al: An integrated genomic analysis of human glioblastoma multiforme. Science 321: 1807-1812, 2008.

16. Mardis ER, Ding L, Dooling DJ, Larson DE, McLellan MD, Chen K, Koboldt DC, Fulton RS, Delehaunty KD, McGrath SD, et al: Recurring mutations found by sequencing an acute myeloid leukemia genome. N Engl J Med 361: 1058-1066, 2009. 
17. Amary MF, Bacsi K, Maggiani F, Damato S, Halai D, Berisha F, Pollock R, O'Donnell P, Grigoriadis A, Diss T, et al: IDH1 and IDH2 mutations are frequent events in central chondrosarcoma and central and periosteal chondromas but not in other mesenchymal tumours. J Pathol 224: 334-343, 2011.

18. Chan-On W, Nairismägi ML, Ong CK, Lim WK, Dima S, Pairojkul C, Lim KH, McPherson JR, Cutcutache I, Heng HL, et al: Exome sequencing identifies distinct mutational patterns in liver fluke-related and non-infection-related bile duct cancers. Nat Genet 45: 1474-1478, 2013

19. Cairns RA, Iqbal J, Lemonnier F, Kucuk C, de Leval L, Jais JP, Parrens M, Martin A, Xerri L, Brousset P, et al: IDH2 mutations are frequent in angioimmunoblastic T-cell lymphoma. Blood 119: 1901-1903, 2012

20. Fassan M, Simbolo M, Bria E, Mafficini A, Pilotto S Capelli P, Bencivenga M, Pecori S, Luchini C, Neves D, et al: High-throughput mutation profiling identifies novel molecular dysregulation in high-grade intraepithelial neoplasia and early gastric cancers. Gastric Cancer 17: 442-449, 2014.

21. Sjöblom T, Jones S, Wood LD, Parsons DW, Lin J, Barber TD, Mandelker D, Leary RJ, Ptak J, Silliman N, et al: The consensus coding sequences of human breast and colorectal cancers. Science 314: 268-274, 2006.

22. Kang MR, Kim MS, Oh JE, Kim YR, Song SY, Seo SI, Lee JY, Yoo NJ and Lee SH: Mutational analysis of IDH1 codon 132 in glioblastomas and other common cancers. Int J Cancer 125 353-355, 2009

23. Ye D, Ma S, Xiong Y and Guan KL: R-2-hydroxyglutarate as the key effector of IDH mutations promoting oncogenesis. Cancer Cell 23: 274-276, 2013.

24. Mondesir J, Willekens $\mathrm{C}$, Touat $\mathrm{M}$ and de Botton S: IDH1 and IDH 2 mutations as novel therapeutic targets: Current perspectives. J Blood Med 7: 171-180, 2016.

25. Xu W, Yang H, Liu Y, Yang Y, Wang P, Kim SH, Ito S, Yang C, Wang P, Xiao MT, et al: Oncometabolite 2-hydroxyglutarate is a competitive inhibitor of $\alpha$-ketoglutarate-dependent dioxygenases. Cancer Cell 19: 17-30, 2011.

26. Molenaar RJ, Radivoyevitch T, Maciejewski JP, van Noorden CJ and Bleeker FE: The driver and passenger effects of isocitrate dehydrogenase 1 and 2 mutations in oncogenesis and survival prolongation. Biochim Biophys Acta 1846: 326-341, 2014.

27. Dang L, Jin S and Su SM: IDH mutations in glioma and acute myeloid leukemia. Trends Mol Med 16: 387-397, 2010.

28. Colvin H, Nishida N, Konno M, Haraguchi N, Takahashi H, Nishimura J, Hata T, Kawamoto K, Asai A, Tsunekuni K, et al: Oncometabolite D-2-Hydroxyglurate directly induces epithelial-mesenchymal transition and is associated with distant metastasis in colorectal cancer. Sci Rep 6: 36289, 2016.

29. Koivunen P, Lee S, Duncan CG, Lopez G, Lu G, Ramkissoon S, Losman JA, Joensuu P, Bergmann U, Gross S, et al: Transformation by the (R)-enantiomer of 2-hydroxyglutarate linked to EGLN activation. Nature 483: 484-488, 2012.

30. Intlekofer AM, Dematteo RG, Venneti S, Finley LW, Lu C, Judkins AR, Rustenburg AS, Grinaway PB, Chodera JD, Cross JR, etal: Hypoxiainduces production of L-2-hydroxyglutarate. Cell Metab 22: 304-311, 2015

31. Hur W, Ryu JY, Kim HU, Hong SW, Lee EB, Lee SY and Yoon SK: Systems approach to characterize the metabolism of liver cancer stem cells expressing CD133. Sci Rep 7: 45557, 2017.

32. Lee SH, Jung YD, Choi YS and Lee YM: Targeting of RUNX3 by miR-130a and miR-495 cooperatively increases cell proliferation and tumor angiogenesis in gastric cancer cells. Oncotarget 6 : $33269-33278,2015$.
33. Pompella A, Visvikis A, Paolicchi A, De Tata V and Casini AF: The changing faces of glutathione, a cellular protagonist. Biochem Pharmacol 66: 1499-1503, 2003.

34. Olsson AK, Dimberg A, Kreuger J and Claesson-Welsh L: VEGF receptor signalling - in control of vascular function. Nat Rev Mol Cell Biol 7: 359-371, 2006.

35. Sternlicht MD and Werb Z: How matrix metalloproteinases regulate cell behavior. Annu Rev Cell Dev Biol 17: 463-516, 2001.

36. Delahousse J, Verlingue L, Broutin S, Legoupil C, Touat M, Doucet L, Ammari S, Lacroix L, Ducreux M, Scoazec JY, et al: Circulating oncometabolite D-2-hydroxyglutarate enantiomer is a surrogate marker of isocitrate dehydrogenase-mutated intrahepatic cholangiocarcinomas. Eur J Cancer 90: 83-91, 2018.

37. Ferrara N, Gerber HP and LeCouter J: The biology of VEGF and its receptors. Nat Med 9: 669-676, 2003

38. Li S, Chou AP, Chen W, Chen R, Deng Y, Phillips HS, Selfridge J, Zurayk M, Lou JJ, Everson RG, et al: Overexpression of isocitrate dehydrogenase mutant proteins renders glioma cells more sensitive to radiation. Neuro-oncol 15: 57-68, 2013.

39. Lee DC, Sohn HA, Park ZY, Oh S, Kang YK, Lee KM, Kang M, Jang YJ, Yang SJ, Hong YK, et al: A lactate-induced response to hypoxia. Cell 161: 595-609, 2015.

40. Schoors S, De Bock K, Cantelmo AR, Georgiadou M, Ghesquière B, Cauwenberghs S, Kuchnio A, Wong BW, Quaegebeur A, Goveia J, et al: Partial and transient reduction of glycolysis by PFKFB3 blockade reduces pathological angiogenesis. Cell Metab 19: 37-48, 2014.

41. Lu C, Ward PS, Kapoor GS, Rohle D, Turcan S, Abdel-Wahab O, Edwards CR, Khanin R, Figueroa ME, Melnick A, et al: IDH mutation impairs histone demethylation and results in a block to cell differentiation. Nature 483: 474-478, 2012.

42. Ferrara $\mathrm{N}$ and Adamis AP: Ten years of anti-vascular endothelial growth factor therapy. Nat Rev Drug Discov 15: 385-403, 2016

43. Franco M, Man S, Chen L, Emmenegger U, Shaked Y, Cheung AM, Brown AS, Hicklin DJ, Foster FS and Kerbel RS: Targeted anti-vascular endothelial growth factor receptor-2 therapy leads to short-term and long-term impairment of vascular function and increase in tumor hypoxia. Cancer Res 66 : 3639-3648, 2006.

44. Bazzazi H, Isenberg JS and Popel AS: Inhibition of VEGFR2 activation and its downstream signaling to ERK1/2 and calcium by thrombospondin-1 (TSP1): In silico investigation. Front Physiol 8: 48, 2017.

45. Rafii S, Lyden D, Benezra R, Hattori K and Heissig B: Vascular and haematopoietic stem cells: Novel targets for anti-angiogenesis therapy? Nat Rev Cancer 2: 826-835, 2002.

46. Bertolini F, Shaked Y, Mancuso P and Kerbel RS: The multifaceted circulating endothelial cell in cancer: Towards marker and target identification. Nat Rev Cancer 6: 835-845, 2006.

47. Curiel TJ, Cheng P, Mottram P, Alvarez X, Moons L, Evdemon-Hogan M, Wei S, Zou L, Kryczek I, Hoyle G, et al: Dendritic cell subsets differentially regulate angiogenesis in human ovarian cancer. Cancer Res 64: 5535-5538, 2004. 